\title{
Histopathological spectrum of lesions of tonsil- A 2 year experience from tertiary care hospital of Maharashtra, India
}

\author{
Sulhyan K.R. ${ }^{1}$, Deshmukh B.D ${ }^{2}$, Wattamwar R.P ${ }^{3}$ \\ ${ }^{1}$ Dr .(Mrs.) Kalpana Ranjit singh Sulhyan, Professor and Head, ${ }^{2}$ Dr. Bhakti Dattatraya Deshmukh, Assistant Professor, \\ ${ }^{3}$ Dr. Reshma Pramod Wattamwar, P.G student, all authors are affiliated with Department of Pathology, Government \\ medical college, Miraj Maharashtra, India
}

Address for correspondence: Dr. Reshma Pramod Wattamwar, Email: meereshma@gmail.com

\begin{abstract}
Background: Palatine tonsils are paired masses of lymphoid tissue which act as immunologic barrier against the entry of pathogenic agents into the respiratory and digestive tracts. Despite their protective function, tonsils are prone to infection. Tonsillitis is a common disease especially among the children. Chronic tonsillitis is a disease with repeated attacks of acute tonsillitis or a sub clinic form of a resistant or poorly treated infection. Aim: To study histopathology of various lesions of tonsil. Material and Methods: We studied histopathology of 211 cases representing surgical samples from 115 patients [Tonsillectomy- 104 patients (Unilateral-08, Bilateral-96) and tonsillar biopsy in 11 patients]. Representative bits were taken from formalin fixed tonsillectomy specimens whereas biopsies were submitted entirely. Routine hematoxylin and eosin staining was done. Results: Amongst 211 cases, histopathological examination in 190 cases showed tonsillitis. The other lesions were cartilaginous choristoma in six patients, epidermal inclusion cyst in three cases and reactive lymphoid hyperplasia in one case. One case of inflammatory my fibroblastic tumors was observed. The malignancies were observed in ten cases- squamous cell carcinoma in nine cases and Non-Hodgkin lymphoma in one case.
\end{abstract}

Key words: Tonsillitis, Tonsillectomy, Histopathology, Chronic, Tonsil

\section{Introduction}

The palatine tonsils are paired nodular masses of lymphoid tissue situated on either side of the oropharynx having an extremely remarkable role in the antimicrobial defense of the body [1,2]. They are covered by non-keratinized stratified squamous epithelium along with deep crypts that invaginate into the parenchyma, in which B-lymphocyte are found [3]. Despite their presumed protective function, tonsils are prone to infection. Tonsillitis is one of the commonest infectious disease seen commonly in the young age group. Various organisms including viruses like Reo virus, Adenovirus, Influenza virus and Echo virus, and bacteria like beta hemolytic streptococcus are implicated in causation of tonsillitis. Rarely, it can be caused by Fungi or parasites [1]. Tonsillectomy is generally indicated when there are

Manuscript received: $05^{\text {th }}$ December 2016

Reviewed: $12^{\text {th }}$ December 2016

Author Corrected: $20^{\text {th }}$ December 2016

Accepted for Publication: $31^{\text {st }}$ December 2016 frequent attacks of acute tonsillitis. Other indications of tonsillectomy include obstructive sleep apnea, quinsy and suspicion of malignancy.

\section{Material and Methods}

Place of study- Department of Pathology in Government medical college, Miraj. Maharashtra.

Type of study - Prospective observational study

Sample collection - The specimens were received in different forms [Tonsillectomy- 104 patients (Unilateral-08, Bilateral-96) and tonsillar biopsy in 11 patients]. Thus, we studied histopathology of 211 cases representing surgical samples from 115 patients.

Sampling methods- The specimens were fixed in $10 \%$ formalin. Representative bits were taken from tonsillectomy specimens whereas biopsies were submitted entirely. The tissue bits were processed to 
make paraffin blocks. The sections were cut at 3-4 micron thickness and were stained with Hematoxylin and Eosin. Microscopic examination was done.
Inclusion criteria- All tonsillectomy and tonsillar biopsy specimens received in our department.

\section{Results}

The age range in our study was 01-97 years with mean age of 20.2 years. Majority of the patients (65.2\%) were aged below 20 years. A slight predominance of female (55.65\%) was noted. The patients presented with varied symptoms like recurrent tonsillitis associated with hypertrophy of tonsils, difficulty or pain while swallowing and tonsillar mass or ulcer. Amongst 211 cases, histopathological examination showed varied non-neoplastic and neoplastic lesions. (Table 1) Inflammatory pathology was seen in 190 cases. (13- Acute tonsillitis and 177- Chronic tonsillitis) Five cases of chronic tonsillitis showed actinomycotic colonies, however there was no tissue reaction. Cartilagenous choristoma, an incidental finding, was observed in six cases. Out of six cases of cartilaginous choristoma, four were women and two were men with an age range of 11 to 30 years. All six patients presented with non-specific complaints like pain in throat and difficulty in swallowing. Epidermal inclusion cyst was observed in three cases. All the three were women, aged 25, 35, 60 years respectively. One case showed only reactive lymphoid hyperplasia. One case of inflammatory myofibroblastic tumour was diagnosed in a 23 year old man who presented with tonsillar mass. The malignancies observed were squamous cell carcinoma in nine cases and Non-Hodgkin lymphoma in one case. Seven out of nine patients of squamous cell carcinoma were men while two were women. All the patients complained of difficulty in swallowing and tonsillar mass or ulcer. One case of Nonhodgkin lymphoma was observed in a 35 year old man. Out of 11 tonsil biopsy specimens, 10 were neoplastic, while in one case biopsy was done from an ulcer which proved to be inflammatory.

\section{Table No.-1: Distribution of Cases on the basis of histopathology}

\begin{tabular}{|c|c|c|c|}
\hline Sr No & Diagnosis & No Of cases & Percentage\% \\
\hline 1 & Acute tonsillitis & 13 & $6.16 \%$ \\
\hline 2 & Chronic tonsillitis & 177 & $83.88 \%$ \\
\hline 3 & Cartilage Choristoma & 06 & $2.84 \%$ \\
\hline 4 & Epidermal inclusion cyst & 03 & $1.42 \%$ \\
\hline 5 & Reactive lymphoid hyperplasia & 01 & $0.47 \%$ \\
\hline 5 & Inflammatory myofibroblastic tumour & 01 & $0.47 \%$ \\
\hline 6 & Squamous cell carcinoma & 01 & $4.26 \%$ \\
\hline 7 & Non-hodgkin Lymphoma & $\mathbf{2 1 1}$ & $0.47 \%$ \\
\hline & Total & $\mathbf{1 0 0 \%}$ \\
\hline
\end{tabular}

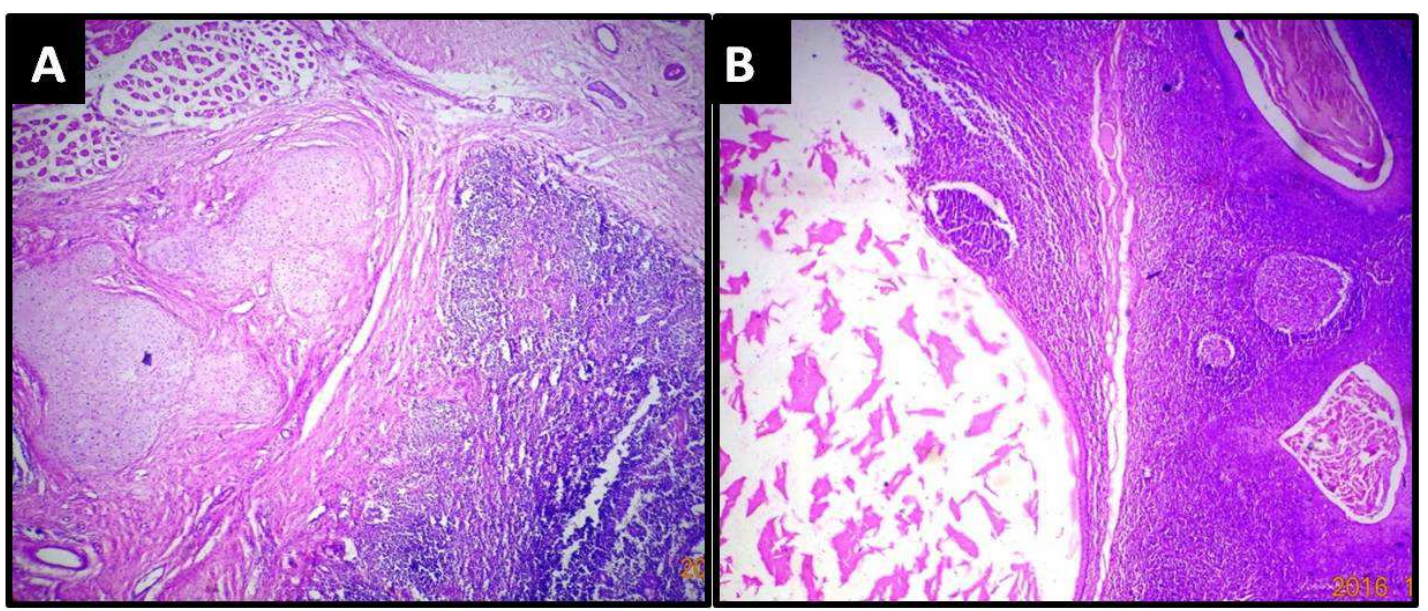

Figure-1: Photomicrograph showing A-Well-defined cartilagenous nest embedded within tonsillar tissue(choristoma) (H \& E, X100). B- Epidermal inclusion cyst lined by stratified squamous epithelium and containing keratin debris.(H\& E, $\mathrm{X} 100)$ 


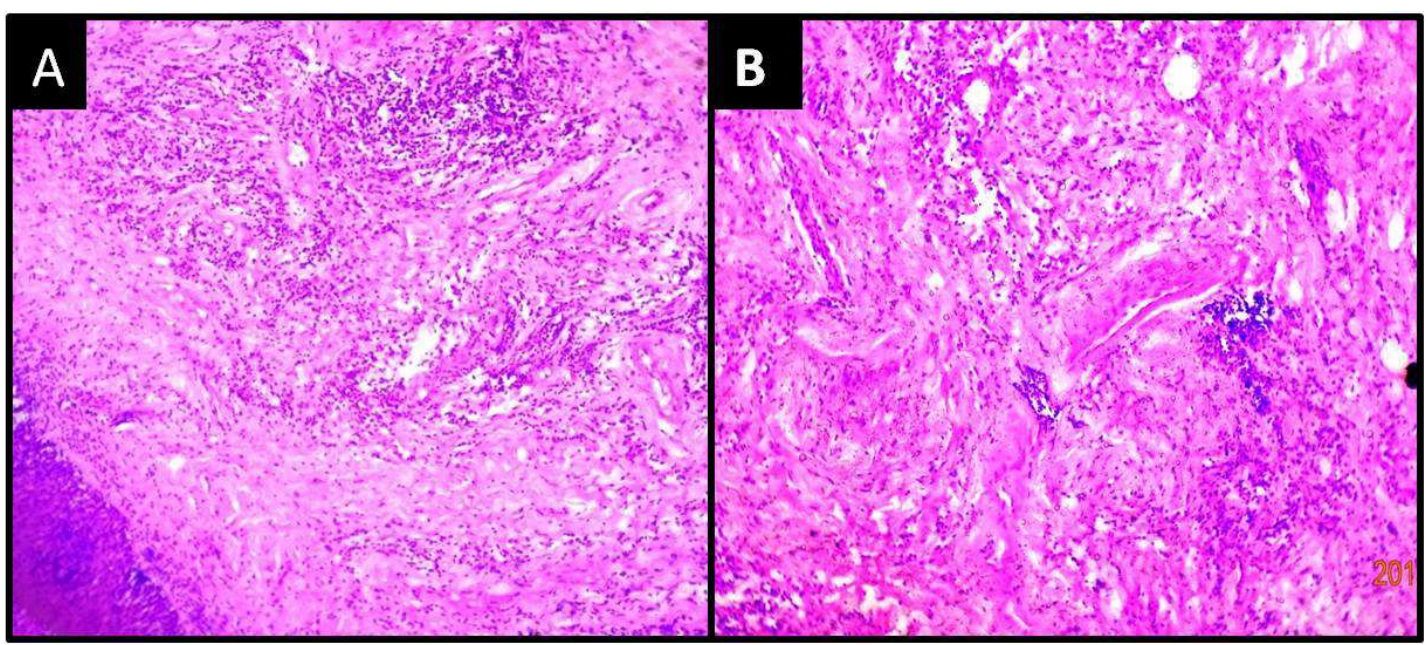

Figure-2: A and B - Inflammatory myofibroblastic tumor - Spindle shaped cells arranged in vague fascicles against loose myxoid background. Note, admixture of plasma cells and lymphocytes. (H\&E, X100)

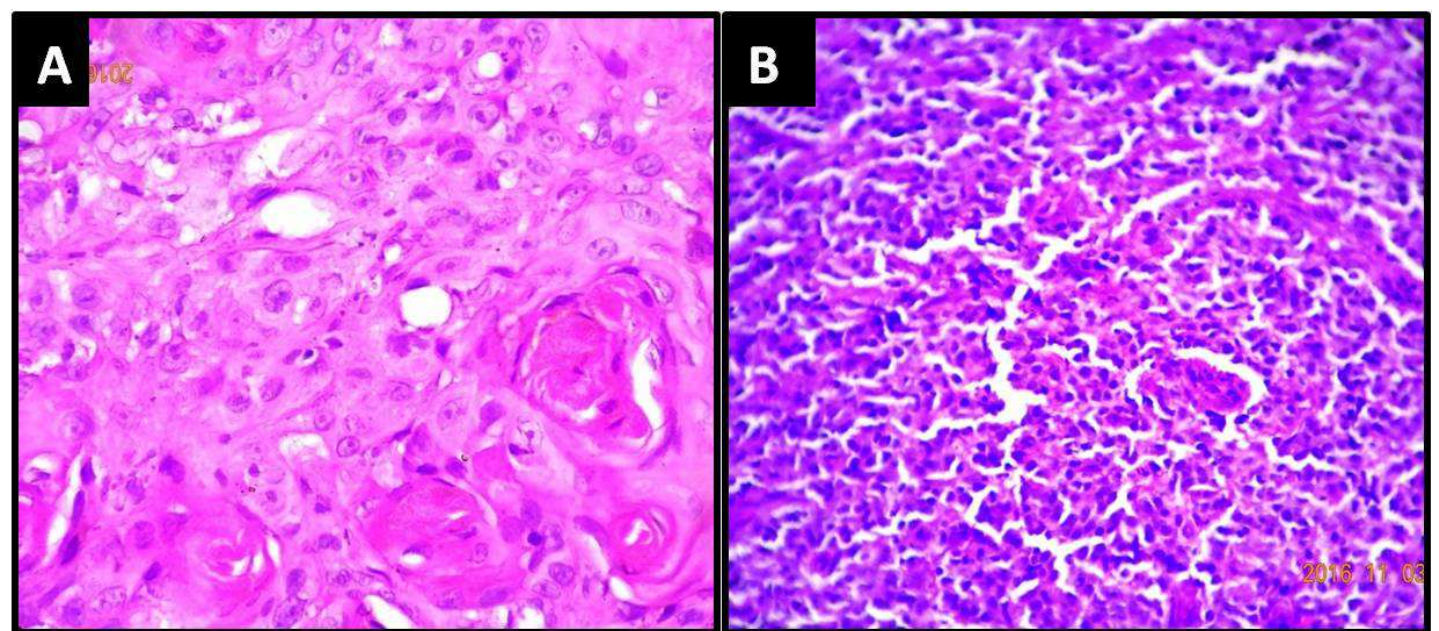

Figure-3: Photomicrograph showing A-Round to polyhedral cells with abundant eosinophilic cytoplasm and few keratin pearls- Squamous cell carcinoma (H\& E, X400). B- Medium sized neoplastic lymphoid cells with hyperchromatic nuclei - Non-Hodgkin Lymphoma (H\& E, X400)

\section{Discussion}

Chronic tonsillitis most often affects children, but can be seen in adults, probably due to a local dysfunction of the epithelium. The recurrent nature of acute tonsillitis is attributed to the bacteria surviving intracellularly, thus avoiding antibiotic killing and causing re-infection. Repeated attacks of tonsillitis can lead to tonsillar hypertrophy causing airway obstruction, thus leading to excision. Many studies stated that though chronic inflammation is present in both tonsillitis and tonsillar hypertrophy, it is more marked in tonsillitis patients. Fibrosis can only be seen in cases of tonsillitis. However, high bacterial load and elevation of immunologically active cell population in the tonsils are observed in both groups of patients [4]. Ugras et al [5] investigated eight histopathologic criteria in all palatine tonsils: 1- Presence of slight-moderate lymphocyte infiltration in the surface epithelium, 2- Presence of abscess leading to the defect in the surface epithelium (Ugras's abscess), 3- Presence of diffuse lymphocyte infiltration leading to the defect in the surface epithelium, 4- Presence of polymorpho nuclear leukocytes in the surface epithelium and in the sub epithelial area, 5- Presence of lymphoid hyperplasia, 6Increase in the plasma cells number in the sub epithelial area and in the interfollicular area, 7- Presence of fibrosis and 8- Presence of atrophy. Seven out of eight criteria they studied were more closely associated with chronic tonsillitis, only one criteria (the presence of lymphoid hyperplasia) was higher in chronic tonsillar hypertrophy compared chronic tonsillitis. 
A choristoma, a rare entity of academic interest, is an aggregate of microscopically normal cells or tissues occurring at aberrant locations. Cartilaginous choristoma was first described by Berry in 1890 [6]. Mature cartilage is not a normal constituent of nasopharyngeal epithelium and therefore presence of cartilage in tonsil represents a choristoma. It is histologically characterized by the diffuse deposits of calcium and scattered cartilaginous cell arranged in various stages of maturation in single or clustered cartilaginous foci. In all our cases, a focus of mature cartilage was seen without calcification. The age of diagnosis for these patients varied greatly ranging from 10-80 years [7]. A high index of suspicion for choristomas is needed, when a patient with recurrent tonsillitis is being evaluated.

Actinomyces are branching filamentous gram-positive bacilli, residing as commensals in the oral cavity. The clinical significance of presence of actinomyces in tonsils and its role in pathogenesis of tonsillitis is a topic of debate for long [8]. Van Lierop et al [9] found no tissue reaction due to actinomyces colonies and hence reported no correlation between tonsillar actinomycosis and recurrent tonsillitis. A similar observation was made by Toh et al[10] in his study of 834 specimens. Contrary to this, Aydin et al [11] analyzed 1820 tonsillectomy specimens and reported that cryptitis was a common histopathologic indicator of tonsillar actinomycosis. Assimakopoulos et al [12] concluded that Actinomyces colonisation of the tonsillar crypts was significant in causing chronic tonsillitis. Several other authors have also studied histopathological sections from tonsillectomy specimens and have arrived at similar conclusions. All these studies report a positive tissue reaction to Actinomyces colonies in the tonsils [8]. In our study, five cases of chronic tonsillitis showed actinomycotic colonies, however there was no tissue reaction.

A variety of cysts can arise in the tonsil with tonsillar retention cyst being the most common. Epidermoid cyst, lymphoepithelial cyst, hydatid cyst are other rare causes of tonsillar cyst [13]. Epidermal inclusion cyst is also called as epidermal cyst, epithelial cyst, keratin cyst, or epidermoid cyst [14]. The inclusion cysts can be found in areas where embryonic elements fuse together (congenital) or can be acquired (post-traumatic). Irrespective of origin, there is no difference between them clinically or histologically [15]. Various studies have been postulated in its pathogenesis, that include the inclusion of ectodermal tissues during embryogenesis, metaplasia in response to prolonged irritation due to chronic infection, and implantation of epithelium at the site of trauma [14]. Histopathologically, it shows a cyst lined by stratified squamous epithelium with a granular layer and is filled with lamellated keratin material. In three of our cases, the tonsils showed evidence of focal lymphoid hyperplasia along with a cyst lined by stratified squamous epithelium containing keratin flakes, Few cyst macrophages and lymphocytes were also seen. Epidermoid cysts can be associated with certain hereditary syndromes like Gardner syndrome and basal cell nevus syndrome [16].

Inflammatory myofibroblastic tumors (IMT) are uncommon lesions occurring primarily in the lung. IMTs of the head and neck region account for 14-18\% of extra-pulmonary IMTs [17]. A debate occurred regarding whether IMTs were pseudo-tumors or neoplasms and whether they were benign or malignant. Later it was proved that IMT shows anaplastic lymphoma tyrosine kinase (ALK) gene rearrangements as a recurrent aberration [18]. The world Health Organization classification currently defines IMT as an intermediate soft-tissue tumor comprising spindle cells that exhibit myofibroblast differentiation and numerous inflammatory cells, plasma cells, and/or lymphocytes. The prognosis of IMTs depends on the surgical margin, tumor size, ALK expression and necrosis [19]. Most patients with an IMT have good prognosis and can be cured by resection. Immunohistochemically, approximately $50 \%$ of IMTs are positive for ALK [18]. Lazaridou et al [20] reviewed the literature and found that ALK expression was not positive for sinonasal IMTs. In their 25-cases, only one patient showed ALK1 positivity. Luo et al [21] reported six cases of tonsillar IMT. These cases comprise two males and four females, and the mean age was 43 years (10-63 years). Clinical symptoms included laryngeal pain, odynophagia, pain in the neck, cough and dyspnea. Our case was diagnosed in a 23 year old man who presented with tonsillar mass. The clinical presentation and gross pathologic features of IMT may mimic a malignancy. Histologically, IMTs are composed of myofibroblasts and inflammatory cells in varying proportions. like lymphocytes, plasma cells, eosinophils, and macrophages. Fujii et al[22] divided IMTs into the lymphocyte type, granulomatous type and sclerosing type according to their histological features, but most researchers do not agree with this view. Coffin et al[23] 
recognized three basic histologic patterns of extra pulmonary IMT: (i) Nodular fasciitis-like (showing myxoid, vascular areas, and inflammatory cells); (ii) Fibrous histiocytoma-like (showing compact spindle cells with intermingled inflammatory cells); and (iii) Desmoid or scar-like (showing dense plate-like collagen). These three patterns could overlap. Our patient belonged to subgroup (i).

Two- thirds of the patients with tonsillar carcinomas present at advanced stages because early lesions are generally asymptomatic when small [24]. Carcinoma arising from these sites usually is squamous in origin and is related strongly to smoking, HPV infection and, to a lesser degree, alcohol ingestion [25]. Most commonly, carcinoma affects patients in the fifth to seventh decade in life. The incidence is 2 to 5 times greater in men than in women [24]. Squamous cell carcinoma (SCC) is the most common malignancy followed by Non-Hodgkin's lymphomas (NHL) in the tonsil. NHL of the oral cavity and oropharynx usually account for $13 \%$ of all primary extra nodal NHL with approximately $70 \%$ occurring in the tonsils [26]. The palatine tonsil is the most frequently involved site followed by palate, gingiva and tongue. Most tonsillar NHLs are B-cell type, with diffuse large B-cell lymphoma representing most of the cases. The peak incidence is in sixth and seventh decades of life with slight male predominance. Clinical presentation is not specific and is due to of asymmetrical tonsillar enlargement [26]. Babu et al [24] reported a total of 5 cases of tonsillar malignancy- two undifferentiated carcinomas, two NHLs, and one SCC. In our study, we observed nine cases of SCC and one case of NHL.

\section{Conclusion}

Though tonsillitis is the commonest lesion diagnosed, histopathology plays an important role in diagnosis of various other non-neoplastic and neoplastic lesions of tonsil.

Funding: Nil, Conflict of interest: None initiated, Permission from IRB: Yes

\section{References}

1. Alnori HA, Mahmod KA, Mohammed AM. Bacteriological, Serological and Histopathological Study on Tonsillectomy Specimens. The Iraqi postgraduate medical journal 2014;13:219-225
2. Mogoanta CA, Ionita E, Pirici D, Mitroi M, Anghelina FL, Ciolofan $\mathrm{S}$ et al. chronic tonsillitis: histological and immunohistochemical aspects. Romanian Journal of Morphology and Embryology 2008, 49(3):381-386

3. Singh I. Lymphatics and Lymphatic Tissue Textbook of human histology. $4^{\text {th }}$ ed. Jaypee brothers medical publishers, India. 2002.pg 191

4. Mal RK, Oluwasanmi AF, Mitchard JR. tonsillar crypts and bacterial invasion of tonsils: Clin Otolaryngol. 2008 Jun;33(3):293-5. doi: 10.1111/j.1749-4486.2008.01691.x.

5. Ugras S, Kutluhan A. Chronic tonsillitis can be diagnosed with Histopathological findings. Eur J Gen Med 2008;5:95-103

6. Bhargava D, Raman R, Khalfam Al Abri R, Bushnurmath B. Heterotopia of the tonsil. J Larangol Otol 1996; 10(6): 611-12

7. Ambawade VD, Sonawane SS, Kothavade HV, Kate MS. Catilagenous Choristoma of Palatine Tonsil- Rare Entity. National Journal of Laboratory Medicine. 2014;3: 16-17. DOI:NJLM/2014/7280:2008

8. Priyadarshini SA, Shubhashree AR, Ganapathy H. Actinomycosis of tonsils- incidental or pathological?- A case report. Int J Pharm Bio Sci 2014; 5(4):164 - 168.

9. van Lierop AC, Prescott CA, Sinclair-Smith CC. An investigation of the significance of Actinomycosis in tonsil disease. Int J Pediatr Otorhinolaryngol. 2007 Dec;71(12):1883-8. Epub 2007 Oct 4.

10. Toh ST, Yuen HW, Goh YH. Actinomycetes colonization of tonsils: a comparative study between patients with and without recurrent tonsillitis. J Laryngol Otol 2007;121:775-8. DOI:10.1017/S0022215106003185.

11. Aydin A, Erkiliç S, Bayazit YA, Koçer NE, Ozer E, Kanlikama M. Relation between actinomycosis and histopathological and clinical features of the palatine tonsils: a comparative study between adult and pediatric patients. Rev LaryngolOtolRhinol 2005;126:95-8

12. Assimakopoulos D, Vafiadis M, Askitis P, Sivridis E, Skevas A. The incidence of Actinomyces israeli 
colonization in tonsillar tissue. A histopathological study. Rev Stomatol Chir Maxillofac 1992;93:122-6.

13. Shobha K, Kumar H, Raj D, Srinivasa K, Jayaganesh. Epidermoid Cyst in Tonsil- a rare presentation. Transworld Medical Journal 2014;2(1): $75-76$.

14. Gulia SP, Lavanya M, Kamidi V, ArunKumar SP. Epidermoid cyst of the tonsil: An incidental finding. Int J Adv in Case reports 2015;2:777-779

15. Janarthanam J, Mahadevan S. Epidermoid cyst of submandibular region. J Oral Maxillofac Pathol 2012;16:435-437. DOI: 10.4103/0973-029X.102511

16. Rajendran R. Develpomental disturbances of oral and para oral structures. Shafers textbook of oral pathology. 6th ed. Elsevier publication a division of Reed Elsevier India private limited Noida (UP), 2009,pg.67-9.

17. Ong HS, Ji T, Zhang CP, Li J, Wang LZ, Li RR et al. Head and neck inflammatory myofibroblastic tumor (IMT): evaluation of clinicopathologic and prognostic features. Oral Oncol. 2012 Feb;48(2):141-8. doi: 10.1016/j.oraloncology.2011.09.004. Epub 2011 Oct 19.

18. Coffin CM, Hornick JL, Fletcher CD. Inflammatory myofibroblastic tumor: comparison of clinicopathologic, histologic, and immunohistochemical features including ALK expression in atypical and aggressive cases. Am J Surg Pathol 2007; 31: 509-520. DOI:10.1097/01.pas.0000213393.57322.c7

19. Coffin CM, Fletcher JA. Inflammatory myofibroblastic tumour. In: Fletcher CDM, Bridge JA, Hogendoorn PCW, Mertens F, editors. World Health Organization classification of tumours. WHO classification of soft tissue and bone. 4th edition. Lyon: IARc Press; 2013. pp. 83-84.

20. Lazaridou M, Dimitrakopoulos I, Tilaveridis I, Iordanidis F, Kontos K. Inflammatory myofibroblastic tumour of the maxillary sinus and the oral cavity. Oral Maxillofac Surg. 2014 Mar;18(1):111-4. doi: 10.1007/s10006-013-0409-2. Epub 2013 Apr 17.

21. Lu ZJ, Zhou SH, Yan SX, Yao HT. Anaplastic lymphoma kinase expression and prognosis in inflammatory myofibroblastic tumours of the maxillary sinus. J Int Med Res. 2009 Nov-Dec;37(6):2000-8.

22. Fujii H, Fujisada H, Kondo T, Takahashi T, Okada S. Orbital pseudotumor: histopathological classification and treatment. Ophthalmologica 1985;190:230-42.

23. Coffin CM, Watterson J, Priest JR, Dehner LP. Extrapulmonary inflammatory myofibroblastic tumor (inflammatory pseudotumor). A clinicopathologic and immunohistochemical study of 84 cases. Am J Surg Pathol 1995; 19: 859-872.

24. Babu AP, Mallik P, Pradhan S, Sobita P, Sudhiranjan TH, Bhutia NN. Tonsillar malignancyReview of clinic-pathological presentation, diagnosis and current treatment modalities: A case series. J Med Soc 2013;27:147-150. DOI: $10.4103 / 0972-$ 4958.121598 .

25. Johansen LV, Overgaard J, Overgaard M, Birkler N, Fisker A. Squamous cell carcinoma of the oropharynx: an analysis of 213 consecutive patients scheduled for primary radiotherapy. Laryngoscope. 1990 Sep;100(9):985-90.

26. Vasilakaki T, Myoteri D, Tsavari A, Skafida E, Arkoumani E, Koulia K, et al. Localised extranodal non-Hodgkin's lymphoma of the tonsil: report of a rare case. OA Case Reports 2013;10;2(11):101-2.

\section{How to cite this article?}

Sulhyan K.R., Deshmukh B.D, Wattamwar R.P. Histopathological spectrum of lesions of tonsil- A 2 year experience from tertiary care hospital of Maharashtra, India. Int J Med Res Rev 2016;4(12):2164-2169.doi:10.17511 /ijmrr. 2016.i12.14. 